\title{
Electrical activation of hydrogen peroxide for organic contaminant degradation using an improved gas diffusion cathode
}

\author{
LUO Haijian ${ }^{a}$, LI Chaolin ${ }^{b}$, SUN Xue $^{c}$, JIANG Jiao ${ }^{d}$
}

Environmental Science and Engineering Research Center, Shenzhen Graduate School, Harbin

Institute of Technology, Shenzhen, 518055, PR China.

aluohaijian123@163.com, ${ }^{\mathrm{b}}$ lichaolin@hit.edu.cn, ${ }^{\mathrm{C}}$ huanxiongwl@163.com, ${ }^{\mathrm{d}}$ 1473067439@qq.com

Keywords: Gas diffusion cathode; Hydrogen peroxide; Electro-Fenton; Phenol

Abstract: Electrochemical degradation technology, being an environment-friendly way for the elimination of a broad-range of organic contaminants from water, is limited by low efficiency and high cost. In this study, an improved gas diffusion electrode (GDE) was constructed by rolling carbon black and polytetrafluoroethylene as conductive catalyst layer to improve the hydrogen peroxide production. The maximum concentration of $259.6 \mathrm{mM}$ was obtained after $60 \mathrm{~min}$, which is roughly eight times higher than the value obtained using the traditional reference cathode. Experiments indicated that the degradation of phenol in the electrochemical process was dominated by radical based mechanisms, which was obtained by the electro-generation and the subsequent electro-activation of hydrogen peroxide at the cathode interface.

\section{Introduction}

Electrochemical advanced oxidation processes, (EAOPs) are considered environmentally friendly emerging alternatives for the abatement of pollution caused by a multitude of organic micro pollutants in waters [1]. Among EAOPs, Electro-Fenton process is one of the most widely used in situ electrochemical technology to control pollution through redox processes involving either direct oxidation, or through synergistic systems based on the power of an oxidant species generated in situ [2]. In this process, hydrogen peroxide is generated in situ from the two-electron reduction of oxygen on cathodes surface, while the continuous regeneration of ferrous iron at the cathode [3], thus avoiding $\mathrm{Fe}^{3+}$ accumulation in the medium and consequently eliminating the production of iron sludge.

Theoretically the performance of the effective destruction of pollutants in electro-Fenton system is substantially dependent on the $\mathrm{H}_{2} \mathrm{O}_{2}$ production, thus an ideal cathode with high production of $\mathrm{H}_{2} \mathrm{O}_{2}$ is vital and becomes one major concern in this area [4]. Generally, the catalytic performance of $\mathrm{H}_{2} \mathrm{O}_{2}$ production is mainly affected by the catalytic material, structure and reaction conditions. So far, carbonaceous materials such as graphite, reticulated vitreous carbon, activated carbon fiber, carbon sponge, carbon/graphite felt and carbon/PTFE composite electrodes are widely used as cathodes due to the advantages such as no toxicity, good stability, high conductivity, and low catalytic activity of $\mathrm{H}_{2} \mathrm{O}_{2}$ decomposition [5]. In addition, the e $\square$ ciency of the process is also somewhat limited by the low solubility of oxygen in water [2]. Over the past decades, this challenge was solved by substituting conventional plane electrodes for a gas di $\square$ usion electrode (GDE) in which hydrogen peroxide is formed in situ at the cathode without the need for the oxygen feed gas to be dissolved in the electrolyte solution [6]. The design of a GDE allows an unlimited supply of gaseous reagents to pass through the porous structure to the electrode/electrolyte interface [4], thus preventing mass transport limitation of the reaction of interest. In the electrolytic process, the catalytic layer faces to electrolyte while the gas diffusion layer faces to reactant gas that diffuses through micro-pores of the GDE to the catalytic layer and reacts with electrolyte at the interface between the electrolyte and the reactant gas.[7]

Currently, GDE using as cathode for in-situ electrosynthesis of $\mathrm{H}_{2} \mathrm{O}_{2}$ have been mainly focused on various carbon-based materials and its modification. However, the effects of the cathodes construction were usually neglected. The effective conduction of proton/electron and access of 
reactant gas depend on the cathode structure [8]. Traditionally, the design of the gas diffusion layer is vital to the gas transfer and waterproof management, while the catalyst layer is crucial to oxygen reduction reaction (ORR) kinetics and three-phase interfaces [9]. Especially, a well-designed catalyst layer improves the uniform gas diffusion and favors the reaction process [10]. In present work, a novel structure of GDE prepared by rolling carbon black and polytetrafluoroethylene (PTFE) was introduced to the electrolytic process. Compared with the conventional GDE system, the improved GDE was proved greatly enhancing $\mathrm{H}_{2} \mathrm{O}_{2}$ productivity, as well as removal efficiency of organic contaminant.

\section{Effect of current density}

The applied current is the driving force for the reduction of oxygen leading to the generation of $\mathrm{H}_{2} \mathrm{O}_{2}$ at the cathode. Several current density in the range of $20-80 \mathrm{~mA} / \mathrm{cm}^{2}$ were applied to determine the effect of for current density on $\mathrm{H}_{2} \mathrm{O}_{2}$ concentration. As seen in Fig.1, the $\mathrm{H}_{2} \mathrm{O}_{2}$ concentration increases with increasing current density from 20 to $60 \mathrm{~mA} / \mathrm{cm}^{2}$, and then there was considerable decrease in $\mathrm{H}_{2} \mathrm{O}_{2}$ concentration above the current value of $60 \mathrm{~mA} / \mathrm{cm}^{2}$. These phenomenon can be explained by using the cell potential. It is noted that there is close relationship between current density and cell potential. Higher applied current density means higher applied potential on the electrochemical system, also more tend to increase the hydrogen evolution reaction[11]. At the current density higher that $60 \mathrm{~mA} / \mathrm{cm}^{2}, \mathrm{H}_{2} \mathrm{O}_{2}$ concentration decreased dramatically. It implies that a high potential accelerate the subsequent decomposition of $\mathrm{H}_{2} \mathrm{O}_{2}$ as well as $\mathrm{H}_{2}$ evolution [11], thus reduce the $\mathrm{H}_{2} \mathrm{O}_{2}$ accumulate concentration and the current efficiency.

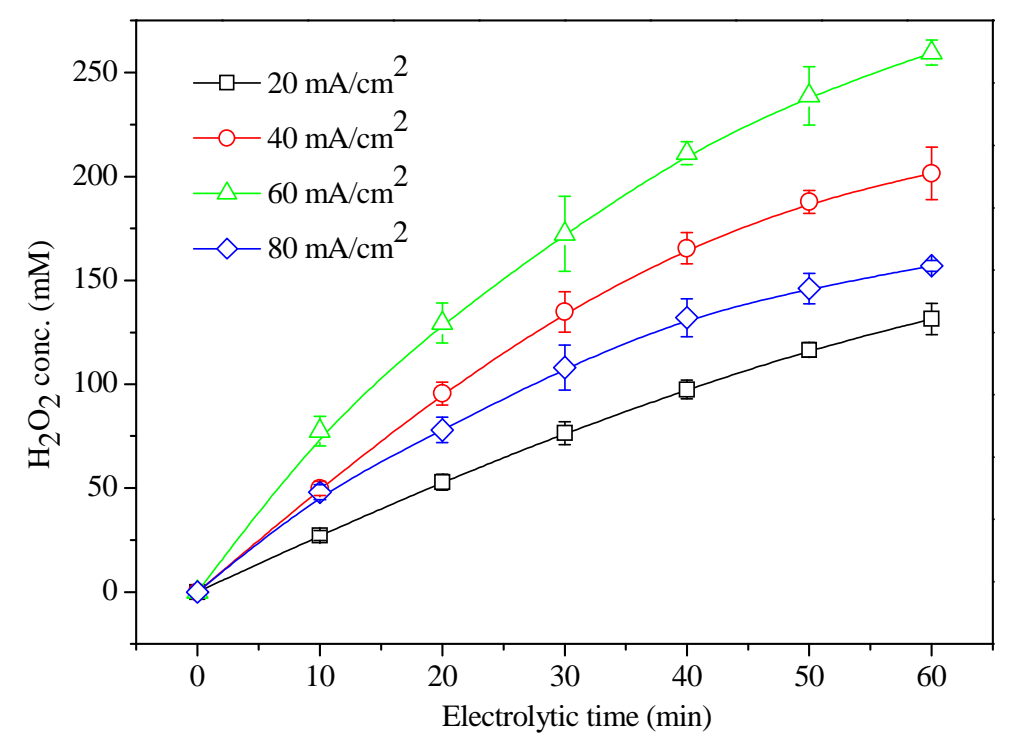

Fig. 1 Effects of current density on $\mathrm{H}_{2} \mathrm{O}_{2}$ concentration. Reaction conditions: $0.1 \mathrm{~mol} / \mathrm{L} \mathrm{Na}_{2} \mathrm{SO}_{4}, 40$ $\mathrm{mL} / \mathrm{min}$ air flow rate, $\mathrm{pH}=3.0$.

\section{Performance of the GDE in an electro-Fenton process.}

Phenol was used as target pollutant to clarify the electro-catalytic activity of the IGDE in an electro-Fenton wastewater treatment process (Fig. 2). In comparison, $\mathrm{H}_{2} \mathrm{O}_{2}$ alone outside the electrolytic system cannot cause any significant degradation of phenol. The phenol removal increased with increasing $\mathrm{Fe}^{2+}$ concentration from 0 to $0.5 \mathrm{mM}$ and does not increase significantly as the dosage of ferrous ions increased. It is noted that, without any $\mathrm{Fe}^{2+}$ catalyst, the GDE also shown an excellent performance in the degradation of phenol, suggesting the production of steady-state concentration of - OH radicals. This is in agreement with that obtained by Wang et al.[9], who has been proved that, without any metal catalyst, $\mathrm{OH} \bullet$ could be produced on a C/PTFE gas-diffusion electrode for the electrochemical oxidation of chlorophenols, and argued that the more $\mathrm{H}_{2} \mathrm{O}_{2}$ yield, the more $\mathrm{OH} \bullet$ 
produced. Compared with $\mathrm{H}_{2} \mathrm{O}_{2}$ concentration of $8 \mathrm{mg} / \mathrm{L}$ produced in C/PTFE gas diffusion cathode [9], more than $250 \mathrm{mM} \mathrm{H}_{2} \mathrm{O}_{2}$ was accumulated in present work, leading to a shorter time for phenol removal as a result of more $\mathrm{OH} \bullet$ produced.

Suitable ferrous ion concentration is an important prerequisite in the electro-Fenton process [12]. The efficient degradation of phenol using electro-Fenton processes can be explained by the fact that Fe (II) ions react with $\mathrm{H}_{2} \mathrm{O}_{2}$ to produce the hydroxyl radical that attacks the $\pi$ system of the aromatic phenolic ring in a rapid manner, resulting in an efficient degradation $[13,14]$. The increase in the removal efficiency was due to the increase in hydroxyl radical concentration as a result of the increase of $\mathrm{H}_{2} \mathrm{O}_{2}$ (Eq. (1)). On the other hand, the efficiency of electro-Fenton process increases with increases with the increase in $\mathrm{Fe}^{2+}$ concentration because the concentration of hydroxyl radical [5], which is the main oxidizing agent in the elelctro-Fenton process. Besides, The negative effect of the higher catalyst concentration on the degradation kinetic can be explained by increase of the rate of the waste reaction occurring between the hydroxyl radicals and the excess of ferrous ions. Therefore, the $\mathrm{Fe}^{2+}$ concentration of $0.2 \mathrm{mM}$ was considered as the appropriate amount for the electro-Fenton process in the novel diaphragm electrolysis device. In this study, an efficient degradation of phenol was made possible by the fact that adequate $\mathrm{H}_{2} \mathrm{O}_{2}$ was continuously electro-generated by the GDE, thus shortening degradation time and enhancing its efficiency.

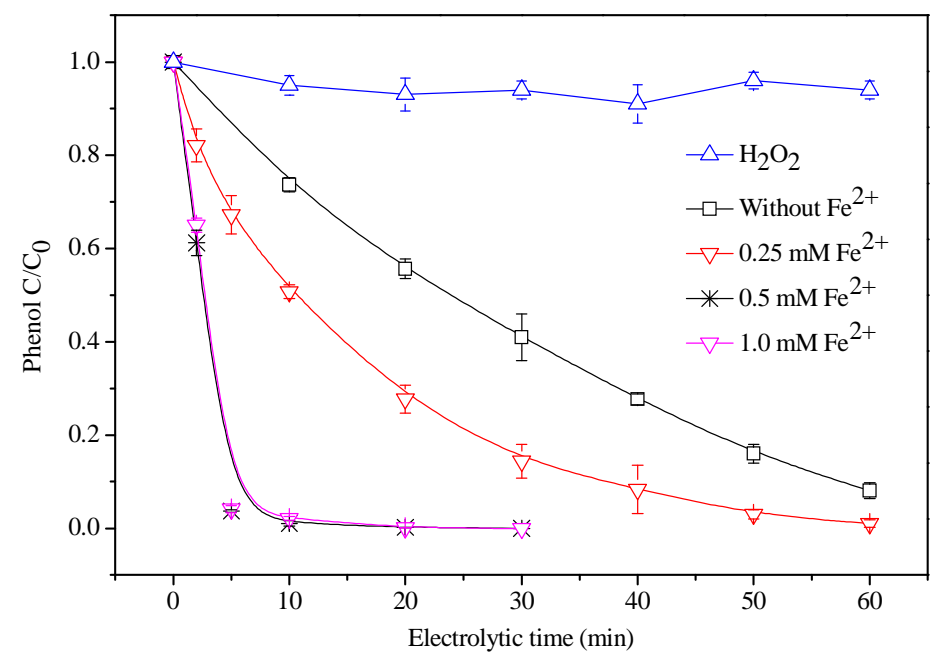

Fig. 2 Effects of ferrous concentration on phenol removal. Reaction conditions: current density of $60 \mathrm{~mA} / \mathrm{cm}^{2}, 0.1 \mathrm{~mol} / \mathrm{L} \mathrm{Na}_{2} \mathrm{SO}_{4}, \mathrm{pH} 3.0$, gas flow rate of $40 \mathrm{~mL} / \mathrm{min}, 100 \mathrm{mg} / \mathrm{L}$ phenol.

\section{Electrical activation of $\mathrm{H}_{2} \mathrm{O}_{2}$ and its mechanisms}

To verify the mechanisms of phenol degradation by electrical activation of $\mathrm{H}_{2} \mathrm{O}_{2}$, a series of comparative experiments were carried out: (a) air as gaseous sources for the GDE, (b) nitrogen as gaseous sources and $\mathrm{H}_{2} \mathrm{O}_{2}$ added externally (1.0 wt \% contained), (c) nitrogen as gaseous sources, and (d) $\mathrm{H}_{2} \mathrm{O}_{2}$ alone (1.0 wt \% contained) as oxidant in a beaker experiment. As shown in Fig. 3, negligible phenol removal was obtained when phenol was treated by $\mathrm{H}_{2} \mathrm{O}_{2}$ alone, because of its limited oxidization power $\left(\mathrm{E}_{0}=1.76 \mathrm{~V}\right)$ [15]. In comparison, nitrogen, instead of air, was used as the gas source for phenol degradation. The removal rate of phenol less than $5 \%$ by the electrolytic process feeding with nitrogen under tested conditions within $60 \mathrm{~min}$. The poor degradation efficiency can be attributed to the scarcely any oxidizing substances as a result of the poor $\mathrm{H}_{2} \mathrm{O}_{2}$ produced in the electrolytic process. The results also suggested that $\mathrm{H}_{2} \mathrm{O}_{2}$ was scarcely produced by feeding nitrogen. A slow and incomplete phenol decay (about 30\%) was achieved by the combined nitrogen as gaseous sources and $1.0 \mathrm{wt} \% \mathrm{H}_{2} \mathrm{O}_{2}$ added externally within $60 \mathrm{~min}$, which demonstrates that the electrolysis can also be a useful alternative to activate the formation of $\bullet \mathrm{OH}$ [16]. Moreover, the rated constant ( $\mathrm{k}$ $\left.=0.022 \mathrm{~min}^{-1}\right)$ within the first 10 minutes was far higher than that at the later time $\left(\mathrm{k}=0.001 \mathrm{~min}^{-1}\right)$. This phenomenon is ascribed to the fact that $\mathrm{H}_{2} \mathrm{O}_{2}$ added from outside is more inclined to decompose 
into water than $\bullet \mathrm{OH}$ radicals [27]. In contrast, the electro-generated and electro-activated $\mathrm{H}_{2} \mathrm{O}_{2}$ process demonstrates the fastest and nearly complete phenol degradation within $40 \mathrm{~min}$, with the rate constant reached at $0.083 \mathrm{~min}^{-1}$.

For the Fenton process, it is generally assumed that $\bullet \mathrm{OH}$ radicals can be produced by the reaction between $\mathrm{H}_{2} \mathrm{O}_{2}$ and $\mathrm{Fe}^{2+}$ in acidic medium [17]. However, it is important to stress that, without any metal catalyst, the $\cdot \mathrm{OH}$ was electro-activated on the interface of the GDE during the electrolytic process in our work. Wang et al.[9] have proved that the similar conclusion was obtained by the electron spin resonance spectrum (ESR) experiments, and the more $\mathrm{H}_{2} \mathrm{O}_{2}$ yield, the more conducive to organic contaminant degraded. Compared with $\mathrm{H}_{2} \mathrm{O}_{2}$ concentration of $8 \mathrm{mg} / \mathrm{L}$ produced in Pd/PTFE gas diffusion cathode [9], more than $275.5 \mathrm{mM} \mathrm{H}_{2} \mathrm{O}_{2}$ was accumulated in present work, leading to a shorter time for phenol removal as a result of more $\bullet \mathrm{OH}$ produced.

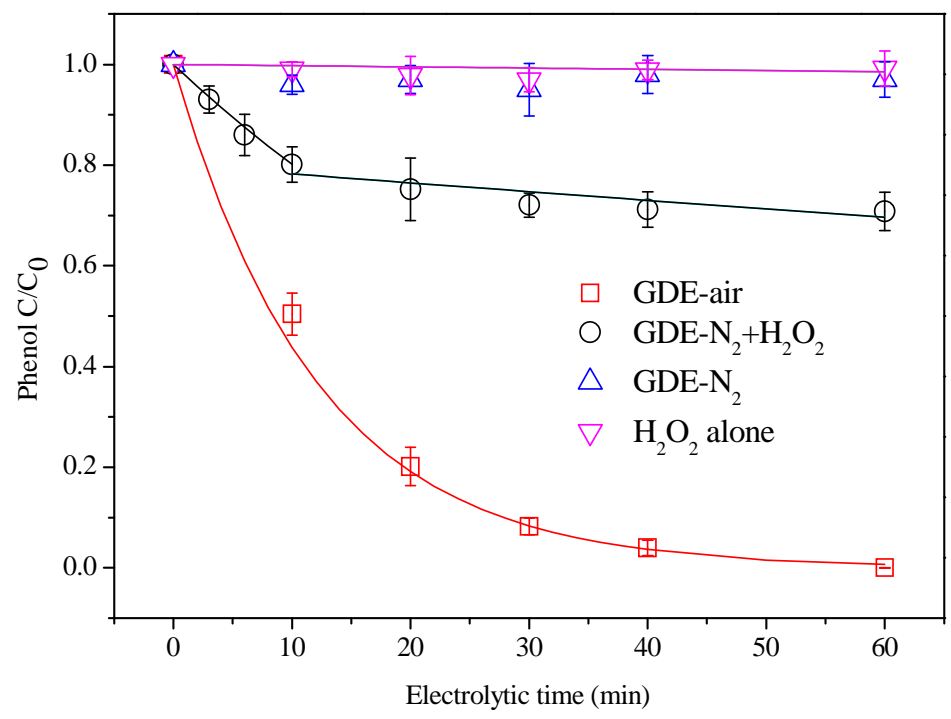

Fig.3 Effects of different systems on phenol removal Reaction conditions: current density of 60 $\mathrm{mA} / \mathrm{cm}^{2}, 0.2 \mathrm{~mol} / \mathrm{L} \mathrm{Na}_{2} \mathrm{SO}_{4}, \mathrm{pH} 4.0$, gas flow rate of $40 \mathrm{~mL} / \mathrm{min}$.

\section{Conclusion}

This study described an efficient method for preparing an improved GDE. The improved GDE not only has a high performance for $\mathrm{H}_{2} \mathrm{O}_{2}$ yield, but also effectively degrade phenol without any metal catalyst. Experiments indicated that the degradation of phenol in the electrochemical process was dominated by radical based mechanisms, which was obtained by the electro-generation and the subsequent electro-activation of $\mathrm{H}_{2} \mathrm{O}_{2}$ at the cathode interface.

\section{Acknowledgements}

This work was supported by the supported of National Natural Science Foundation of China (No. 51678182).

\section{References}

[1] S.D. Sklari, K.V. Plakas, P.N. Petsi, V.T. Zaspalis, A.J. Karabelas, Toward the Development of a Novel Electro-Fenton System for Eliminating Toxic Organic Substances from Water. Part 2. Preparation, Characterization, and Evaluation of Iron-Impregnated Carbon Felts as Cathodic Electrodes, Industrial \& Engineering Chemistry Research 54 (2015) 2059-2073.

[2] R.M. Reis, A.A. Beati, R.S. Rocha, M.H. Assumpcao, M.C. Santos, R. Bertazzoli, M.R. Lanza, Use of gas diffusion electrode for the in situ generation of hydrogen peroxide in an 
electrochemical flow-by reactor, Industrial \& Engineering Chemistry Research 51 (2011) 649-654.

[3] M. Panizza, G. Cerisola, Electro-Fenton degradation of synthetic dyes, Water research 43 (2009) 339-344.

[4] L. Zhou, M. Zhou, Z. Hu, Z. Bi, K.G. Serrano, Chemically modified graphite felt as an efficient cathode in electro-Fenton for p-nitrophenol degradation, Electrochimica Acta 140 (2014) 376-383.

[5] P. Nidheesh, R. Gandhimathi, Trends in electro-Fenton process for water and wastewater treatment: an overview, Desalination 299 (2012) 1-15.

[6] I. Yamanaka, T. Onizawa, S. Takenaka, K. Otsuka, Direct and Continuous Production of Hydrogen Peroxide with 93\% Selectivity Using a Fuel - Cell System, Angewandte Chemie International Edition 42 (2003) 3653-3655.

[7] Y. Sheng, S. Song, X. Wang, L. Song, C. Wang, H. Sun, X. Niu, Electrogeneration of hydrogen peroxide on a novel highly effective acetylene black-PTFE cathode with PTFE film, Electrochim. Acta 56 (2011) 8651-8656.

[8] H. Dong, H. Yu, H. Yu, N. Gao, X. Wang, Enhanced performance of activated carbon-polytetrafluoroethylene air-cathode by avoidance of sintering on catalyst layer in microbial fuel cells, Journal of Power Sources 232 (2013) 132-138.

[9] H. Wang, D.-Z. Sun, Z.-Y. Bian, Degradation mechanism of diethyl phthalate with electrogenerated hydroxyl radical on a Pd/C gas-diffusion electrode, J. Hazard. Mater. 180 (2010) 710-715.

[10] H. Wang, Z. Wu, A. Plaseied, P. Jenkins, L. Simpson, C. Engtrakul, Z. Ren, Carbon nanotube modified air-cathodes for electricity production in microbial fuel cells, Journal of Power Sources 196 (2011) 7465-7469.

[11] H. Luo, C. Li, C. Wu, X. Dong, In situ electrosynthesis of hydrogen peroxide with an improved gas diffusion cathode by rolling carbon black and PTFE, Rsc Adv. 5 (2015) 65227-65235.

[12] M. Zhou, Q. Yu, L. Lei, G. Barton, Electro-Fenton method for the removal of methyl red in an efficient electrochemical system, Separation and Purification Technology 57 (2007) 380-387.

[13] V. Kavitha, K. Palanivelu, The role of ferrous ion in Fenton and photo-Fenton processes for the degradation of phenol, Chemosphere 55 (2004) 1235-1243.

[14] M. Assumpção, R. De Souza, R. Reis, R. Rocha, J. Steter, P. Hammer, I. Gaubeur, M. Calegaro, M. Lanza, M. Santos, Low tungsten content of nanostructured material supported on carbon for the degradation of phenol, Applied Catalysis B: Environmental 142 (2013) 479-486.

[15] J.M. Campos - Martin, G. Blanco - Brieva, J.L. Fierro, Hydrogen peroxide synthesis: an outlook beyond the anthraquinone process, Angewandte Chemie International Edition 45 (2006) 6962-6984.

[16] H. Luo, C. Li, C. Wu, W. Zheng, X. Dong, Electrochemical degradation of phenol by in situ electro-generated and electro-activated hydrogen peroxide using an improved gas diffusion cathode, Electrochim. Acta 186 (2015) 486-493.

[17] Y. Chu, Y. Qian, W. Wang, X. Deng, A dual-cathode electro-Fenton oxidation coupled with anodic oxidation system used for 4-nitrophenol degradation, Journal of hazardous materials 199 (2012) 179-185. 